\title{
De responsieve toezichthouder
}

\author{
Judith van Erp \& Karin van Wingerde
}

\section{Inleiding}

In zijn rapport neemt de WRR krachtig afstand van een te strikte focus op handhaving door toezichthouders. De Raad plaatst kritische kanttekeningen bij 'de nieuwe strengheid' die veel toezichthouders de afgelopen jaren hebben getoond. ${ }^{1}$ In plaats van bestraffing moeten toezichthouders op zijn minst op zoek gaan naar de juiste mix van overleg voeren en druk uitoefenen. Een eenzijdige nadruk op verticale controle doet namelijk geen recht aan de complexiteit en dynamiek van de samenleving. ${ }^{2}$ De WRR bepleit daarom de maatschappelijke functie van toezicht centraal te stellen. ${ }^{3}$ Dat betekent: voorbij de letter van de wet kijken en maatschappelijke problemen proactief benaderen en oplossen. Dat betekent ook oog hebben voor het maatschappelijke krachtenveld waarin ook private en interne toezichthouders actief zijn en aansluiten bij en gebruikmaken van toezicht op andere niveaus. ${ }^{4}$ Dit is in de woorden van de WRR reflectief toezicht: 'toezicht dat signaleert, agendeert, kennis deelt en actief feedback geeft'. ${ }^{5}$

De visie van de WRR weerspiegelt het gedachtegoed zoals dat de afgelopen twintig jaar is ontwikkeld binnen de theoretische stroming responsive regulation (hierna: RR). Deze benadering kan worden gesitueerd in het gelijknamige boek Responsive Regulation, transcending the deregulation debate dat in 1992 werd gepubliceerd door de Amerikaanse econoom Ian Ayres en de Australische criminoloog John Braithwaite. ${ }^{6}$ Sindsdien is RR niet alleen een van de invloedrijkste wetenschappelijke theorieën over toezicht en handhaving, ${ }^{7}$ maar ook ongekend populair in de toezichtpraktijk. Vrijwel elke Nederlandse toezichthouder hanteert een variant van de zogeheten handhavingspiramide: het escalatiemodel voor interventies zoals gepresenteerd door Ayres en Braithwaite. Het adagium speak softly while carrying a big stick ${ }^{8}$ is in Nederland door veel toezichthouders vertaald als 'zacht waar het kan, hard waar het moet' of vergelijkbare motto's. ${ }^{9}$ Ook in het WRR-rapport neemt de handhavingspiramide een belangrijke plaats in.

7 P. Mascini, Why was the enforcement pyramid so influential? And what price was paid?, Regulation \& Governance 2013, 7, p. 48-60.

8 Ayres \& Braithwaite 1992, p. 19.

9 H.G. van de Bunt, J.G. van Erp \& C.G. van Wingerde, Hoe stevig is de piramide van Braithwaite?, Tijdschrift voor Criminologie 2007, 49 (4), p. 386-399.
} 
De populariteit van de handhavingspiramide is opvallend, omdat dit tegelijkertijd een van de meest problematische aspecten is van RR. Immers: een gedifferentieerde benadering van onder toezicht gestelde organisaties - maatwerk in interventies - brengt ongelijkheid mee en botst met de bureaucratische organisatievorm van toezichthouders. ${ }^{10}$ Escalatie is bovendien problematisch wanneer het contact met de onder toezicht gestelde partij zeer infrequent is - regelmatige en terugkerende controles zijn in de praktijk vaak geen vanzelfsprekendheid, waardoor de volgende stap jaren op zich kan laten wachten. In deze bijdrage vragen wij aandacht voor een ander aspect van RR dat in onze ogen veel beter aansluit bij de handhavingspraktijk. Het belangrijkste kenmerk van RR is namelijk dat het de vraag adresseert hoe toezichthouders gebruik kunnen maken van het maatschappelijke krachtenveld dat bestaat uit verschillende publieke en private partijen. ${ }^{11}$ Deze zogenoemde tripartite handhaving is in het Nederlandse debat over toezicht ten onrechte onderbelicht gebleven en biedt aanknopingspunten om aan de maatschappelijke functie van toezicht die de WRR bepleit, verder invulling te geven.

\section{Tripartite handhaving als oplossing voor capture}

Responsive regulation beoogt de klassieke tegenstelling tussen command and control wetgeving enerzijds en vrije marktwerking anderzijds te overstijgen. Het is een pleidooi voor een 'derde weg'. ${ }^{12}$ Een dialoog met onder toezicht gestelde organisaties kan tot meer begrip leiden van de dilemma's en valkuilen bij de implementatie van regelgeving. Daarmee kan een niveau van naleving worden gerealiseerd dat meer betekenisvol is dan de letter van de wet en een betere beheersing biedt van de belangrijkste maatschappelijke risico's. Bovendien zou handhaving die beter aansluit bij de belevingswereld van ondernemingen effectiever kunnen zijn. ${ }^{13}$ Toezichthouders die de dialoog met onder toezicht gestelde organisaties zoeken, riskeren echter tegelijkertijd dat de handhaving te soft en begripvol wordt, dat ze te dicht op ondernemingen komen te zitten en zo hun onafhankelijkheid verliezen. ${ }^{14}$

Binnen RR is er daarom ook een centrale rol weggelegd voor derde partijen in het toezicht, zoals belangengroepen, NGO's, omwonenden en burgers, maar bijvoorbeeld ook verzekeraars en certificerende instanties. Inclusie van derde partijen in het toezicht is noodzakelijk om tegenwicht te bieden aan de macht en de belangen

10 Van de Bunt e.a. 2007; Mascini 2013; C. Parker, Twenty years of responsive regulation: An appreciation and appraisal, Regulation \& Governance 2013, 7, p. 2-13; R. Baldwin \& J. Black, Really Responsive Regulation, The Modern Law Review 2008, 71 (1), p. 59-94.

11 Parker 2013; C. Ford, Prospects for scalability: Relationships and uncertainty in responsive regulation, Regulation \& Governance 2013, 7, p. 14-29.

12 Ayres \& Braithwaite 1992, p. 3.

13 N. Gunningham \& D. Sinclair, Regulation and the role of trust: Reflections from the mining industry, Journal of Law \& Society 2009, 36 (2), p. 167-194; J.G. van Erp, Naming without shaming: the publication of sanctions in the Dutch financial market, Regulation \& Governance 2011, 4 (5), p. 287-308.

14 Parker 2013; Ford 2013. 
van ondernemingen en om toezichthouders scherp te houden. Het uitgangspunt van $R R$ is dat de toezichthoudende overheid, het bedrijfsleven en het publiek door samen te werken maatschappelijke meerwaarde kunnen creëren. RR is een participatieve democratische theorie: alle relevante partijen zitten met elkaar aan tafel om deel uit te maken van het toezichtarrangement. ${ }^{15}$

\section{Tripartite handhaving binnen responsive regulation}

Verreweg het meest omvangrijke hoofdstuk uit responsive regulation is gewijd aan tripartite handhaving. Ayres en Braithwaite definiëren tripartite handhaving als een vorm van handhaving waarbij derde partijen een volwaardige stem hebben in de discussie en besluitvorming over de inzet van toezicht en handhaving. ${ }^{16}$ Dat kan in de eerste plaats worden bereikt door derde partijen toegang te geven tot alle relevante informatie die van belang is voor het toezicht, en hen ook te betrekken in overlegcircuits. Daarnaast moeten derde partijen ook de toegang en mogelijkheden hebben om effectief invloed te kunnen uitoefenen op het gedrag van ondernemingen, maar ook op de handelswijze van toezichthouders, zo nodig via de gang naar de rechter. Bij dat laatste is het vooral van belang dat derde partijen ook in staat worden gesteld om de toezichthouder op zijn functioneren aan te spreken als die overtredingen en misdrijven onbestraft laat. Samengevat betekent tripartite handhaving in de woorden van Ayres en Braithwaite 'both unlocking the smoke-filled rooms where the real business of regulation is transacted and allowing public interest groups to operate as a private attorney general' [cursivering red.]. ${ }^{17}$

Binnen RR is uitgebreid onderzoek gedaan naar de rol en bijdrage van derde partijen in het toezicht. Deze theorie is dan ook bij uitstek geschikt om nader invulling te geven aan de verhouding tussen publieke en private toezichthouders zoals de WRR die bepleit. Want het WRR-pleidooi voor de toezichthouder in het maatschappelijk krachtenveld laat nog veel vragen onbeantwoord. Welke activiteiten onderneemt een 'maatschappelijk georiënteerde' toezichthouder nu precies? Hoe verhoudt samenwerken met maatschappelijke partijen zich tot handhaving? Hoe kan een te grote (feitelijke, morele of cognitieve) interdependentie worden vermeden, hoe voorkom je capture en blijf je als toezichthouder onafhankelijk? Of is dit een illusie? Kun je samenwerken met NGO's en belangengroepen waarvan je het gedrag niet kunt sturen? Wordt samenwerking met het bedrijfsleven en belangengroepen niet door het publiek geïnterpreteerd als deals sluiten? Met andere woorden: hoe organiseer je een zinvolle inbreng van derde partijen in het toezicht? In het vervolg van deze bijdrage gaan wij op enkele van deze vragen in en laten we zien dat het WRR-pleidooi de toezichthouder voor enorme uitdagingen stelt. 


\section{De rol van derde partijen in het toezicht: kansen en risico's}

Responsive regulation werd geschreven vóór het internettijdperk. ${ }^{18}$ Het internet biedt nieuwe manieren voor transparantie en openbaarmaking van toezichtinformatie, waarmee derde partijen hun voordeel kunnen doen. Sociale media kunnen bijvoorbeeld worden gebruikt om informatie over het nalevingsgedrag van bedrijven en instellingen openbaar te maken en te communiceren met burgers en belangengroepen. ${ }^{19}$ Daarnaast biedt het internet aan derde partijen zelf ook ruime mogelijkheden om informatie over bedrijven en instellingen openbaar te maken. Nieuwe initiatieven zoals Wikileaks en Publeaks bieden zelfs zeer laagdrempelige mogelijkheden om misstanden met de buitenwereld te delen.

\section{Sensitiviteit van de toezichthouder}

Maar het is niet genoeg om derde partijen alleen een kanaal te bieden om informatie over het gedrag van bedrijven en instellingen uit te wisselen: de toezichthouder moet ook luisteren naar en reageren op signalen vanuit de maatschappelijke omgeving. Onderzoeken naar vele grote fraudegevallen van de afgelopen jaren in binnen- en buitenland - Enron, Madoff, de bouwfraude - laten zien dat er diverse red flags, tips en meldingen beschikbaar waren, die door toezichthouders zijn genegeerd. ${ }^{20}$ Zowel in de Madoff-zaak als in de bouwfraudezaak klopte een klokkenluider met heldere bewijzen (Markopoulos respectievelijk Bos) tevergeefs aan bij de toezichthouder. Reichman geeft verschillende verklaringen voor dit gebrek aan oplettendheid. ${ }^{21}$ In de eerste plaats tunnelvisie: door een strikte focus op de naleving van de letter van de wet wordt compliance een ritueel zonder inhoud. ${ }^{22}$ Dat wordt nog versterkt wanneer er een gebrek is aan samenwerking tussen (afdelingen binnen) toezichthoudende organisaties. In de Madoff-zaak bijvoorbeeld werkte de SEC in New York niet samen met de afdeling die over de specifieke expertise beschikte om de transacties van Madoff te beoordelen. ${ }^{23}$ Ook in Nederland is de versnippering van toezichthouders veelvuldig aan de orde gesteld. ${ }^{24}$

Als tweede interessante verklaring suggereert Reichman een fundamenteel wantrouwen bij toezichthouders ten aanzien van informatie van derden. Deze derden

18 Ford 2013; P. Grabosky, Beyond responsive regulation: the expanding role of non-state actors in the regulatory process, Regulation \& Governance 2013, 7, p. 114-123.

19 H.H.M. Scholtes, Transparantie, icoon van een dolende overheid, Den Haag: Boom Lemma uitgevers 2012. Zie tevens het themanummer van dit tijdschrift dat volledig gewijd was aan de relatie tussen media en toezicht: TvT 2013, nr. 3.

20 H.G. van de Bunt, Walls of secrecy and silence. The Madoff case and cartels in the construction industry, Criminology \& Public Policy 2010, 9 (3), p. 435-453; N. Reichman, Getting our attention, Criminology \& Public Policy 2010, 9 (3), p. 483-491.

21 Reichman 2010.

22 Vgl. K. Krawiec, Cosmetic compliance and the failure of negotiated governance, Washington University Law Quarterly 2003, 81, p. 487-544.

23 Reichman 2010, p. 487.

24 G.A. Biezeveld \& M.C. Stoové, Naar een Nederlandse Omgevingsautoriteit, TvT 2011, nr. 3, p. 9-33; Commissie Herziening Handhavingsstelsel VROM-regelgeving (commissie-Mans), De tijd is rijp, Den Haag 2008. 
hebben vaak eigen belangen en worden daarmee per definitie als onbetrouwbaar ervaren.

Signalen en vermoedens van ernstige fraude worden vaak ook niet hard genoeg bevonden om in officiële risicoanalyses en omgevingsscans te worden meegenomen. Daarmee wordt waardevolle informatie genegeerd en blijft de handhaving zich richten op de reeds bekende risico's. Toezichthouders moeten in hun risicoanalyses dan ook een grotere waarde toekennen aan soft signals, capaciteit vrijspelen voor vrije denkers die buiten de gebaande paden gaan en het gesprek aandurven met onconventionele partijen. Een mooi voorbeeld hiervan is het inzetten van ethical hackers, veelal ex-hackers, die de overheid helpen bij de bestrijding van allerhande vormen van cybercriminaliteit.

De maatschappelijke omgeving buiten spel?

RR gaat uit van fysieke ontmoetingen (controles, overleg) tussen toezichthouders en ondernemingen, die afgebakend zijn in plaats en tijd. ${ }^{25}$ Het handelen van veel ondernemingen speelt zich echter in belangrijke mate af buiten Europa. Het is maar de vraag in hoeverre toezichthouders, laat staan belangenorganisaties, goed zicht hebben op wat daar gebeurt. Een belangrijk deel van het handelen van ondernemingen is bovendien gesitueerd op internationale markten onder invloed van transnationale reguleringsarrangementen - denk aan de financiële sector, de offshore-industrie of de petrochemische industrie. De WRR gaat in zijn rapport wat al te gemakkelijk uit van de nationale situatie. Hoe organiseer je op internationaal niveau een zinvolle inbreng van derde partijen?

Nog een fundamenteler probleem ontstaat wanneer we denken aan systeemrisico's, risico's die zich niet voordoen op het niveau van de individuele organisatie, maar op het niveau van het collectief. Ford noemt de Basel II-akkoorden over kapitaalvereisten als dramatisch voorbeeld: niet alleen was er een mismatch tussen het nationaal georiënteerde toezicht en de problematiek op het niveau van het mondiale systeem, het probleem deed zich ook voor in een 'fully unregulated nearby space', de over the counter derivatenmarkt. ${ }^{26}$ Deze risico's blijven buiten beeld in de dialoog tussen toezichthouder en onder toezicht gestelde. Hoe kan de maatschappelijke functie van het toezicht op dit niveau worden georganiseerd? De financiële crisis kan zelfs gedeeltelijk worden beschouwd als een product van te zeer coöperatief en dialooggericht toezicht en toont het gevaar van een te gesloten toezichtsarrangement waarin te weinig ruimte is voor onafhankelijke geluiden.

\section{Waarop letten derde partijen?}

Dat roept de vraag op naar de thema's en problematiek waarop derde partijen hun aandacht richten. RR gaat ervan uit dat er belangengroepen zijn die het publieke belang vertegenwoordigen en bereid en in staat zijn om een onderhandelingspartner te zijn. Dit is lang niet altijd het geval. Uit de handhaving van de milieuregel- 
geving zijn vele voorbeelden bekend van belangenorganisaties die zich alleen lijken bezig te houden met het ageren tegen milieubesluiten. Deze partijen worden al snel als 'lastige beroepsklagers' getypeerd. ${ }^{27}$ Dit kan zelfs tot gevolg hebben dat het reageren op de wensen en verwachtingen van derde partijen zoveel tijd en energie kost, dat derde partijen het toezicht lamleggen. ${ }^{28}$

Het tegenovergestelde is het company town syndrome: de situatie dat de maatschappelijke omgeving economisch afhankelijk is van de betreffende bedrijven en daarom niet snel geneigd is bedrijven op hun handelen aan te spreken. Uit onderzoek naar de invloed van derde partijen op het milieugedrag van ondernemingen komt bovendien naar voren dat derde partijen meestal meer aandacht hebben voor meer zichtbare problemen, zoals geur-, geluid- en stofoverlast en dat ernstigere, maar minder zichtbare problemen buiten beeld blijven. ${ }^{29}$ Zeker voor nieuwe en onbekende risico's en problemen is het de vraag of derde partijen in staat zullen zijn deze als zodanig te herkennen en daarop vervolgens actie te ondernemen.

Toezichthouders moeten dan ook soms het veld actief vormgeven en derde partijen faciliteren om hun rol te kunnen vervullen. Reflectief toezicht is daarom niet alleen toezicht dat agendeert en signaleert, maar soms ook regisseert en faciliteert. ${ }^{30}$ Dat betekent in de eerste plaats dat toezichthouders de discussie moeten aangaan en een open mind moeten hebben over wat dan de problemen zijn waar het toezicht zich op zou moeten richten. Maar het betekent ook dat ze actief tegenspraak moeten organiseren en belangengroepen moeten steunen, mogelijk ook financieel. ${ }^{31}$ Een belangrijke vraag daarbij is natuurlijk wel hoe ver toezichthouders daarin kunnen gaan.

\section{Tot besluit}

Met zijn pleidooi voor een maatschappelijk georiënteerde, reflectieve toezichthouder heeft de WRR zich nogal wat op de hals gehaald. In de eerste plaats vraagt dit een rolverandering van de toezichthouder, die zich open zal moeten stellen voor een relatie met een heel nieuw scala aan organisaties. Maar maatschappelijk georiënteerd toezicht vraagt ook om een fundamentele herbezinning op de verhouding tussen markt, staat en civil society, met een grotere rol voor maatschappelijke organisaties die werkelijke macht krijgen. De theorie van RR vestigt er de aandacht op dat dit geen technische en instrumentele opgave is, maar primair een

27 K. de Graaf, J. Jans \& H. Tolsma, Milieuorganisaties door de mangel. De wetgever gepasseerd?, NJB 2009, 2, p. 80-87.

28 C.G. van Wingerde, De afschrikking voorbij. Een empirische studie naar afschrikking, generale preventie en regelnaleving in de Nederlandse afvalbranche, Nijmegen: Wolf Legal Publishers 2012, p. 243-245.

29 N. Gunningham, R. Kagan \& D. Thornton, Shades of Green. Business, Regulation, and Environment, Stanford: Stanford University Press 2003; Van Wingerde 2012, p. 238-239.

30 J.G. van Erp, Lessen voor toezicht in de $21^{\mathrm{e}}$ eeuw; actuele inzichten van Braithwaite en Sparrow, Justitiële Verkenningen 2008, 34 (6), p. 9-21.

31 Toezichthouders moeten 'het lastige gesprek' durven aangaan, zie hierover de bijdrage van Alex Brenninkmeijer elders in dit themanummer. 
politieke. ${ }^{32}$ Maatschappelijk georiënteerde toezichthouders zijn democratische en responsieve toezichthouders die de dialoog met maatschappelijke partijen opzoeken, ook met partijen die nadrukkelijk een tegengeluid laten horen.

In deze bijdrage hebben wij laten zien dat dit zeker geen gemakkelijke opgave is. Veel toezichthoudende instanties in ons land bevinden zich in een ontwikkelstadium en zijn nog niet in staat om antwoord te geven op de complexe vragen die een maatschappelijk georiënteerde toezichthouder met zich brengt. Maar ook de grondleggers van RR, Ayres en Braithwaite, hebben nooit antwoord kunnen geven op de vraag hoe toezichthouders in de praktijk invulling moeten geven aan hun maatschappelijke taak. RR is door Christine Parker dan ook wel getypeerd als 'elegant, inspirational, and impractical. ${ }^{33}$ Voor het WRR-rapport betekent dit dat de implicaties ervan in ieder geval veel groter zijn dan op het eerste gezicht lijkt. Hopelijk zet het rapport aan tot nieuwe experimenten van responsieve toezichthouders om invulling te geven aan hun maatschappelijke taak. 